\title{
Role model: Bob Klaber
} The consultant at the Imperial College Healthcare NHS Trust speaks to Kathy Oxtoby about what
makes paediatrics a wonderful specialty.

\author{
Kathy Oxtoby
}

Paediatrics is a partnership with children, their parents, families, and carers, says Bob Klaber, "You have to put patients and families at the centre of everything. That's what healthcare should be about."

Klaber's own family played a part in his choice of medicine as a career. His mother is a retired GP, his father a retired dermatologist, two of his siblings are GPs, and the third is a speech and language therapist. "So all six of us have worked in or for the NHS," he says.

Growing up, he had a real curiosity about science and loved being around people. Having heard about the pros and cons of the profession "from the supper table every night," he decided in his teens that he wanted to be a doctor. "I've not regretted my choice for one second," he says.

Klaber's desire to work with children also began when he was young. "One of my great loves is sport and when I was at school one of my holiday jobs was to coach children in summer camps," he says.

"When I was sixteen I ran residential country holidays for deprived children from London, as part of a children's charity team. Those experiences showed me how much I enjoyed interacting with, working with, and learning from children. Then, when I did my first placement in paediatrics I absolutely loved it and realised it was the right specialty for me."

Klaber chose to do his clinical training at the Royal London Hospital, because he wanted to experience "a busy, complex, and interesting part of London where patients' needs are diverse." He adds, "I loved it there-it was so full of character and kindness, and it helped set the direction of my career."

Now Klaber holds a number of different roles. He is an acute paediatrician, covering the wards and doing outpatient work, and he co-leads a project called Connecting Care for Children which encourages GPs and other professionals in primary care and hospitals to work together.
As deputy medical director at Imperial College Healthcare NHS Trust, Klaber has established a quality improvement programme "with the aim of teaching and inspiring all staff to be able to improve how we look after patients and the staff experience." In all aspects of his work, Klaber tries to encourage junior doctors. One of the ways he does this is by trying to flatten hierarchies.

"I don't let anybody call me by surname-it's unhelpful and gets in the way of safety as it could prevent people from pointing out that I've missed something or could have done something better. We-consultants and trainees-are all in the same team, and the flatter we make the hierarchy the better. It's about trying to create an environment where other people can thrive."

Klaber has "absolutely no idea" what he'll be doing in 10 years' time but he hopes he will be able to continue to do work that is "a mix of caring for patients, strategic work, and mentoring."

\section{Nominated by Sarah Montgomery-Taylor}

"Bob Klaber is an incredibly positive and infectious person to be around. Even a five minute conversation in the hospital corridor leaves you inspired and excited about opportunities to effect change and get involved in improving care for patients.

"Anyone that's been lucky enough to cross paths with him would agree. Every person who works with Bob is known by name, and is made to feel appreciated for their contribution.

"For me, Bob models how it's possible to give the best care you can to a patient, and at the same time work tirelessly to improve wider systems, process, and services to impact the health of a whole population of children."

Sarah Montgomery-Taylor is a paediatric specialty trainee year 3 at Imperial College Healthcare NHS Trust, London.

Nominations: To nominate someone who has been a role model during your medical career, send their name, job title, and the reason for your nomination to arimmer@bmj.com.

Published by the BMJ Publishing Group Limited. For permission to use (where not already granted under a licence) please go to http://group.bmj.com/group/rights-licensing/ permissions 